\title{
In vivo effects of genistein, herbimycin a and geldanamycin on rat hepatic cytochrome P4501A
}

\author{
Maria L. Perepechaeva*, Alevtina Y. Grishanova
}

Institute of Molecular Biology and Biophysics Siberian Branch of the Russian Academy of Medical Science, Novosibirsk, Russia; *Corresponding Author: perepech@soramn.ru

Received 17 August 2012; revised 17 September 2012; accepted 28 September 2012

\begin{abstract}
Cytochrome P4501A (the CYP1A1 and CYP1A2 enzymes) are regulated through the aryl hydrocarbon receptor (AhR)-dependent signal transduction pathway and are generally known as enzymes which metabolize anthropogenic xenobiotics such as dioxin to carcinogenic and mutagenic compounds. However, recently the facts of CYP1A activation under physiological conditionns or under action of non-dioxin-like compounds appear. In the present study we show that genistein, herbimycin $A$ and geldanamycin (the protein-tyrosine kinase inhibitors) affect in vivo to CYP1A1 activity, the CYP1A1 mRNA level and the CYP1A1 protein level. These data provide insight into the role of protein kinases in CYP1A regulation may facilitate the understanding of CYP1A regulation.
\end{abstract}

Keywords: Protein-Tyrosine Kinase; Aryl Hydrocarbon Receptor; Cytochromes P450 1A Regulation

\section{INTRODUCTION}

Cytochromes $\mathrm{P} 450$ are a superfamily of enzymes that play a critical role in the oxidizing metabolism of a wide range of endogenous and exogenous compounds. Cytochromes P4501A1 (CYP1A1) and 1A2 (CYP1A2) metabolize planar hydrophobic substances such as polycyclic aromatic hydrocarbons and aromatic amines, forming cytotoxic and/or mutagenic products. Until recently, it was thought that CYP1A can only be induced by compounds that are polycyclic and planar in structure; however, recent data have shown that compounds that have different chemical structures can do as much. The mechanisms of "non-classic" CYP1A activation are not yet clear [1].

The aryl hydrocarbon receptor (AhR) is a ligand-dependent transcription factor; it belongs to the family of basic helix-loop-helix (HLH)-periodicity/ARNT/singleminded [Per/ARNT/Sim (PAS)] transcription factors. AhR mediates a spectrum of toxic and carcinogenic effects of polycyclic aromatic hydrocarbons (PAHs) and arylamines by transcriptional activating CYP1A, a subfamily of the cytochrome P450 superfamily [2].

When inactive, AhR is located in the cytoplasm along with its associated proteins, including heat shock protein 90 (Hsp90) (two molecules), co-chaperones and c-Src tyrosine kinase [3]. After AhR binds to its ligand, the above-mentioned complex disintegrates, ligand-bound AhR moves to the nucleus and dimerizes with Arnt (Ah receptor nuclear translocator). The AhR/Arnt heterodimer then binds to xenobiotic responsive elements (XREs) in the CYP1A1/2 gene enhancer, which causes initiation of CYP1A1/2 transcription [2].

Over the past two decades it has been demonstrated repeatedly that not only does AhR function as a receptor for xenobiotics, but also plays an important role in several physiological processes, such as immune response, female reproductive functions, cell cycle progression and others $[4,5]$.

AhR and Arnt are both phosphoproteins, phosphorylated on threonine residues [6]. Human Arnt is phosphorylated on threonine, serine and tyrosine residues [7]. Furthermore, kinases are able to regulate the AhR signal transduction pathway via phosphorylation of CYPs. Posttranslational modifications of CYP2B4, CYP2B1/2 and CYP2E proteins by protein kinase A have been described $[8,9]$. In spite of extensive studies of the AhR-dependent signal transduction pathway, the role of PTKs in the mechanism of CYP1A expression is not yet clear.

Kinase activation is a major process, which provides the transmission of environmental information into cells or regulates intracellular signaling pathway activity. Protein-tyrosine kinases (PTKs) are enzymes that catalyze the transfer of the $\gamma$-phosphate from ATP to the hydroxyl group of tyrosine residues on protein substrates. PTKs are the critical components of signal transduction pathways that control cell proliferation and differentiation. In humans, tyrosine kinases have been demonstrated to play 
a significant role in the development of many diseases, including diabetes and cancer [10]. Phosphorylation of signal transduction molecules is a major activating event that leads to dramatic changes in tumor growth. In tumor cells, it is common that key PTKs are no longer adequately controlled, and excessive phosphorylation sustains signal transduction pathways in an activated state [11]. The therapeutic strategy used in this case consists in blocking PTK using PTK inhibitors. New treatment regimens are permanently being elaborated all over the world using different types of PTK inhibitors.

The aims of the present study were to explore possible effects of the nonspecific competitive PTK inhibitor genistein and the Src PTK and Hsp90 inhibitors herbimycin $\mathrm{A}$ and geldanamycin on CYP1A in the rat liver in vivo.

\section{METHODS}

\subsection{Reagents}

Acrylamide, tris(hydroxymethyl)aminomethane, NADPH, bovine serum albumin and SIGMA FAST TM 5-bromo-4-chloro-3-indolyl phosphate/Nitro blue tetrazolium tablets, 3,3'-diaminobenzidine tetrahydrochloride tablets were purchased from Sigma-Aldrich (USA); N,N'-Methylenebisacrylamide, dimethyl sulfoxide (DMSO), HEPES and TEMED from Serva (Germany); 2-Mercaptoethanol from Ferak Berlin (Germany); $\mathrm{MgCl}_{2}$ from Janssen Chimica (Belgium); ethylenediaminetetraacetic acid (EDTA) from Merck (Germany); RNAsecure Reagent from Ambion, Inc. (USA); 7-ethoxyresorufin, 7methoxyresorufin, M-MuLV reverse transcriptase, RNa$\sin ^{\circledR}$ and RQ1 DNase from Promega (USA); DNA molecular weight markers from Sibenzyme (Russia); Taq polymerase, dNTP and dithiothreitol (DTT) from Medigen (Russia); the VektoRNK-ekstraktsiya RNA isolation kit from Vector-Best (Russia); oligonucleotides for analysis of CYP1A1, CYP1A2, $\beta$-actin and random hexanucleotide primers from BIOSSET (Russia) and Medigen (Russia); genistein, herbimycin A and geldanamycin from A.G. Scientific Inc. (USA). All other chemicals were obtained from other commercial sources and were analytical grade.

\subsection{Animals}

Male Wistar rats weighing 150 - $200 \mathrm{~g}$ from the stock maintained at the Animal Facility of the Institute of $\mathrm{Cy}$ tology and Genetics, SB RAS, (Novosibirsk, Russia) were used. The animals were housed in plastic cages under standard conditions (12:12 h light/dark regimen; food and water available ad libitum). All experimental procedures were approved by the Animal Care Committee of the Institute of Molecular Biology and Biophysics, SB RAMS (Novosibirsk, Russia). The rats were subse- quently anesthetized with ethyl ester and sacrificed by decapitation.

\subsection{Exposure to Tyrosine Kinase Inhibitors}

The experimental rats were injected (intraperitoneally) with genistein ( $5 \mathrm{mg} / \mathrm{kg}$ body weight) in DMSO, herbimycin A (33 $\mu \mathrm{g} / \mathrm{kg}$ body weight) in DMSO, or geldanamycin $(50 \mu \mathrm{g} / \mathrm{kg}$ body weight) in DMSO once a day for 5 days (the most effective dose determined in preliminary experiments). The animals in the control group received DMSO intraperitoneally once a day for 5 days.

\subsection{Preparation of Rat Liver Microsomes}

Rat liver microsomes were prepared by differential ultracentrifugation [12]. The livers were perfused with cold buffer $1.15 \% \mathrm{KCl}, 20 \mathrm{mM}$ Tris- $\mathrm{HCl}$ ( $\mathrm{pH} 7.4)$, removed and homogenized in the same buffer. Liver homogenates were centrifuged for $20 \mathrm{~min}$ at $10,000 \mathrm{~g}$, and the resulting supernatants were centrifuged for $60 \mathrm{~min}$ at $105,000 \mathrm{~g}$. The final pellets were resuspended in $0.1 \mathrm{M} \mathrm{KH}_{2} \mathrm{PO}_{4}$ buffer ( $\mathrm{pH} 7.4$ ) containing $20 \%$ glycerol. Protein concentrations were measured using the Lowry method [13] with bovine serum albumin as a standard.

\subsection{Enzyme Assays}

The selective activities of the CYP1A isoforms 7-ethoxyresorufin-O-deethylase (CYP1A1) and 7-methoxyresorufin-O-demethylase (CYP1A2) were measured using the spectrofluorometric method described by Burke and colleagues [12].

\subsection{RNA Isolation}

Total RNA was isolated using a VektoRN K-ekstraktsiya RNA isolation kit as per the manufacturer's protocol. The RNA pellets were dissolved in $1 \mathrm{mM}$ sodium citrate buffer, $\mathrm{pH}$ 6.5, containing $1 \times$ RNA secure reagent. RNA concentration was determined by UV spectrophotometry, and its integrity was verified by agarose gel electrophoresis with ethidium bromide staining. The RNA extracts were treated with RNase-free DNase to remove contaminating DNA. The reaction mixture contained $5 \mu \mathrm{g}$ of total RNA, 1 unit of RQ1 RNase-Free DNase, 1x reaction buffer and 20 units of $\mathrm{RNasin}^{\circledR}$ in a $20 \mu \mathrm{L}$ reaction volume.

\subsection{Reverse Transcription}

The mixture contained $400-800$ ng of total RNA, reaction buffer ( $50 \mathrm{mM}$ Tris- $\mathrm{HCl}$ (pH 8.3), $75 \mathrm{mM} \mathrm{KCl,} 3 \mathrm{mM}$ $\mathrm{MgCl}_{2}$ and $10 \mathrm{mM}$ DTT), $1 \mathrm{mM}$ dNTPs, 200 units of $\mathrm{M}-\mathrm{MuLV}$ reverse transcriptase, $4 \mu \mathrm{g}$ of random hexamer primers, 25 units of $\mathrm{RNasin}^{\circledR}$ in a $25 \mu \mathrm{l}$ reaction volume. 
The samples were incubated for 120 minutes at $37^{\circ} \mathrm{C}$.

\subsection{Multiplex Polymerase Chain Reaction}

We used the following PCR primers: for CYP1A1, forward 5'-CTGGTTCTGGATACCCAGCTG-3' and reverse 5'-CCTAGGGTTGGTTACCAGG-3', amplicon size 331 bp [14]; for CYP1A2, forward

5'-GCAGGTCAACCATGATGAGAA-3' and reverse

5'-CGGCCGATGTCTCGGCCATCT-3', amplicon size

$334 \mathrm{bp}$ [15]; for $\beta$-actin, forward

5'-CGTTGACATCCGTAAAGACCTCTA-3' and reverse

5'-TAAAACGCAGCTCAGTAACAGTCCG-3', amplicon size 290 bp [16]. $\beta$-actin was used as an internal control (housekeeping gene). PCR was carried out in a total volume of $20 \mu$ in $1 \times$ PCR buffer $(150 \mathrm{mM}$ Tris $\mathrm{HCl} \mathrm{pH}$ $8.3,50 \mathrm{mM} \mathrm{KCl}), 0.25 \mathrm{mM} \mathrm{dNTP}, 1 \mu \mathrm{M}$ of the primers $(0.25 \mu \mathrm{M}$ each of the target gene primers and $0.25 \mu \mathrm{M}$ each of the housekeeping gene primers), 2 units of Taq-polymerase, $2 \mu \mathrm{L}$ of cDNA and $3.5 \mathrm{mM} \mathrm{MgCl}_{2}$. The PCR program started with an initial denaturation at $95^{\circ} \mathrm{C}$ for 3 min followed by 30 or 26 cy- cles of amplification $\left(94^{\circ} \mathrm{C}\right.$ for $15 \mathrm{~s}, 60^{\circ} \mathrm{C}$ for $15 \mathrm{~s}$ and $72^{\circ} \mathrm{C}$ for $\left.15 \mathrm{~s}\right)$ and a final extension at $72^{\circ} \mathrm{C}$ for $4 \mathrm{~min}$. The optimum number of cycles was 30 for CYP1A1 with $\beta$-actin and 26 for CYP1A2 with $\beta$-actin. Each sample was amplified twice. PCR products were separated by electrophoresis in a $2 \%$ agarose gel in $1 \mathrm{x}$ TBE buffer and stained with ethidium bromide PCR bands were visualized using UV light, photographed using a DNA Analyzer video system (Lytech, Russia) and semiquantitated using ImageJ [URL: http://rsb web.nih. gov/ij/ download. html]. The final results were calculated by normalI zing the CYP1A1 and CYP1A2 levels to the $\beta$-actin level.

\subsection{SDS-PAGE Electrophoresis and Immunoblot Analysis. SDS-PAGE Electrophoresis and Immunoblot Analysis}

Sodium dodecyl sulphate polyacrylamide gel electrophoresis (SDS-PAGE) was carried out according to the Laemmli method [17]. For protein identification, $80 \mu \mathrm{g}$ of microsomal proteins were loaded onto each lane of a $10 \%$ acrylamide gel and transferred to a nitrocellulose membrane using Fastblot B34 (Biometra, Germany) as per the manufacturer's protocol. The proteins were then visualized by staining with Ponceau Red. The membrane was blocked with $5 \%$ non-fat dry milk in $1 \times$ TBS buffer $(20 \mathrm{mM}$ tris $-\mathrm{HCl} \mathrm{pH} 7.5,150 \mathrm{mM} \mathrm{NaCl})$ containing $0.05 \%$ Tween 20 overnight at $+4^{\circ} \mathrm{C}$ and incubated for $1 \mathrm{~h}$ at $37^{\circ} \mathrm{C}$ on a shaker. The membrane was washed three times with $0.05 \%$ Tween/TBS and then incubated with antibodies against rat CYP1A1 and CYP1A2 [18] for 1.5 $\mathrm{h}$ at room temperature. After that, the membrane was washed three times with $0.05 \%$ Tween/TBS and incubated with a secondary antibody for $1 \mathrm{~h}$. The proteins under study were visualized using SIGMA FAST ${ }^{\mathrm{TM}} 5$ Bromo-4-chloro-3-indolyl phosphate/Nitro blue tetrazolium tablets (Sigma-Aldrich, USA).

\subsection{Statistical Analysis}

Statistical analyses were performed using the STATISTICA software package (StatSoft, Inc., USA). All data were analyzed using Student's $t$-test and the results confirmed using the Mann-Whitney rank sum test.

\section{RESULTS}

CYP1A1 activity in the liver of the control rats was normalized to a value of 100 . CYP1A1 activity was increased 1.5 -fold by genistein, 1.8 -fold by herbimycin A and 1.7-fold by geldanamycin (Figure 1(a)).

The CYP1A1 mRNA level, too, was increased by these three PTK inhibitors (Figure 1(b)), that induced by herbimycin A (2-fold) being somewhat higher than that induced by geldanamycin (1.4-fold). The increase in the CYP1A1 mRNA level following treatment with genistein did not reach significance, but a trend was clear.

In contrast, none of the PTK inhibitors induced CYP1A2 activity or increased the CYP1A2 mRNA level (Figure 2).

Western blot analysis was used to determine whether PTK inhibitors are capable of affecting the CYP1A1/2 protein level. As can be seen from Figure 3, treatment with any of the PTK inhibitors resulted in a clear-cut induction of CYP1A1 and CYP1A2 apoproteins (admittedly, the magnitudes of induction were different). The CYP1A1 protein level was increased 3.5 -fold by genistein, 3.5 -fold by herbimycin treatment and 5.5 -fold by geldanamycin. The CYP1A2 protein level was increased, too, but to a lesser degree: 1.5 -fold by genistein, 2.5 -fold by herbimycin treatment and 5.5 -fold by geldanamycin.

\section{DISCUSSION}

A schematic view of CYP1A activation molecular mechanism and the probable points of interaction with protein kinases is shown in Figure 4.

The phenomenon of CYP1A induction by "non-classic" compounds has led to extensive studies; however, the mechanisms of "non-classic" CYP1A activation remain to be explained. Some studies have demonstrated that genistein, herbimycin $\mathrm{A}$ and geldanamycin affect CYP1A1 activity, the CYP1A1 mRNA level and the CYP1A1 protein level in vitro following exposure to PAH-like compounds [19-27]; however, there is almost no information about whether and how these PTK inhibitors affect CYP1A1 in vivo following exposure to non-PAH-like 


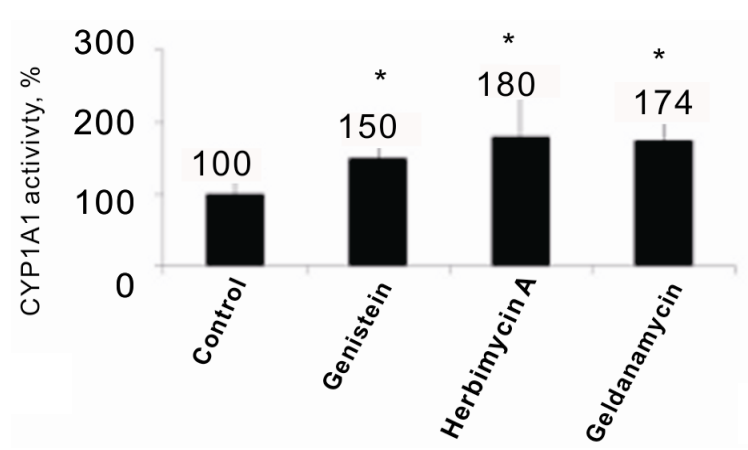

(a)

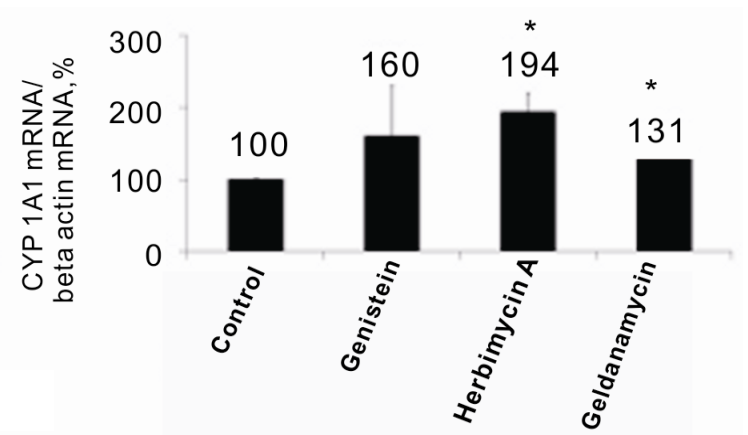

(b)

Figure 1. Effects of PTK inhibitors on (a) CYP1A1 activity and (b) the CYP1A1 mRNA level. Values are presented as mean \pm SEM $(n=3)$. Significant differences from the control group are marked with ${ }^{*}(p<0.05)$.

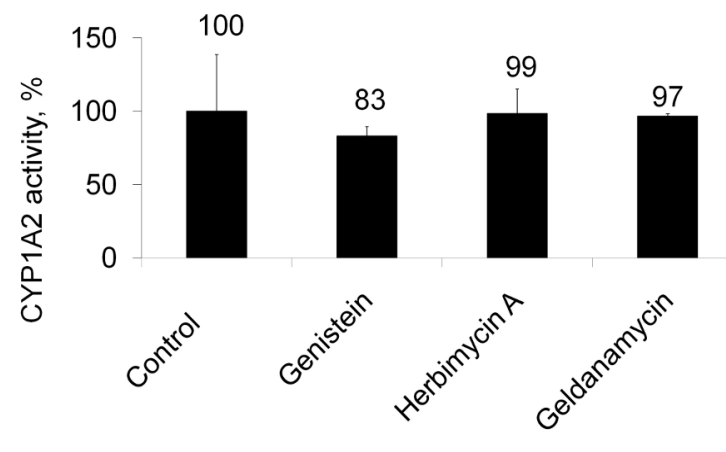

(a)

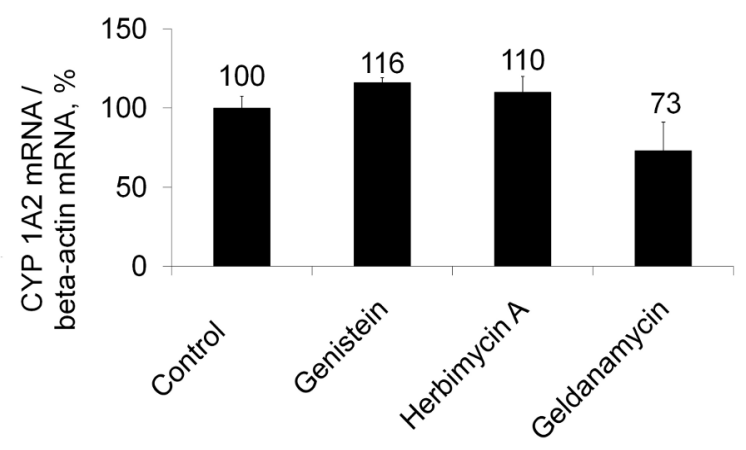

(b)

Figure 2. Effects of PTK inhibitors on (a) CYP1A2 activity and (b) the CYP1A2 mRNA level. Values are presented as mean $\pm \operatorname{SEM}(\mathrm{n}=3)$.

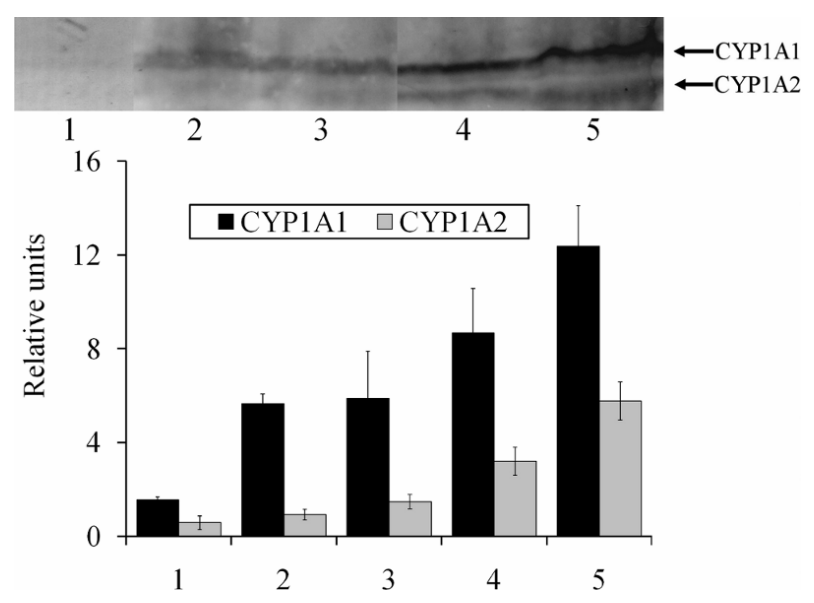

Figure 3. Western blot analysis of CYP1A1 and CYP1A2 proteins in the rat liver microsomes. The microsomal protein samples were applied to $10 \%$ SDS-PAGE, transblotted onto a nitrocellulose membrane and incubated with mouse anti-rat CYP1A1/A2 monoclonal antibody [9]. Each experiment was repeated three times. $80 \mu \mathrm{g}$ of protein were loaded onto each lane. Legend: lane 1-control group; lane 2-animals treated with genistein; lane 3-animals treated with herbimycin A; lane 4-animals treated with geldanamycin; lane 5-animals treated with benz $(\alpha)$ pyrene (dissolved in vegetable oil) at the dose of 5 $\mathrm{mg} / \mathrm{kg}$ body weight/day for 4 days (positive control).
We have now explored the involvement of PTKs in "non-classic" CYP1A activation when the PTK inhibitors were administered to rats in vivo.

According to literature, when classic AhR ligands are used, herbimycin A and geldanamycin inhibit in vitro CYP1A1 activity [19,20], and reduce the CYP1A1 mRNA [21,22], and protein levels [20,23]. Studies of the effects of genistein on CYP1A1 have produced conflicting results. For example, it has been reported that, when classic AhR ligands are used, genistein increases [24], decreases [25] and does nothing [20] to CYP1A1 activity; similarly, some studies have shown that this drug increases [26], decreases [27] and does not change [20] the CYP1A1 mRNA level, and that it increases [26] and does nothing [20] on the CYP1A1 protein level in vitro.

There is a single in vivo study reporting a decrease in CYP1A1 activity, CYP1A1 mRNA level and CYP1A1 protein level by genistein in the rat liver following treatment with 7.12-dimerhyl benzanthracene [28].

Based on these data, we hypothesized that, because the PTK inhibitors reduce CYP1A expression, PTKs may be involved in positive regulation of CYP1A. Our experimental data did not support this hypothesis. The differences between the literature data and our experimental 


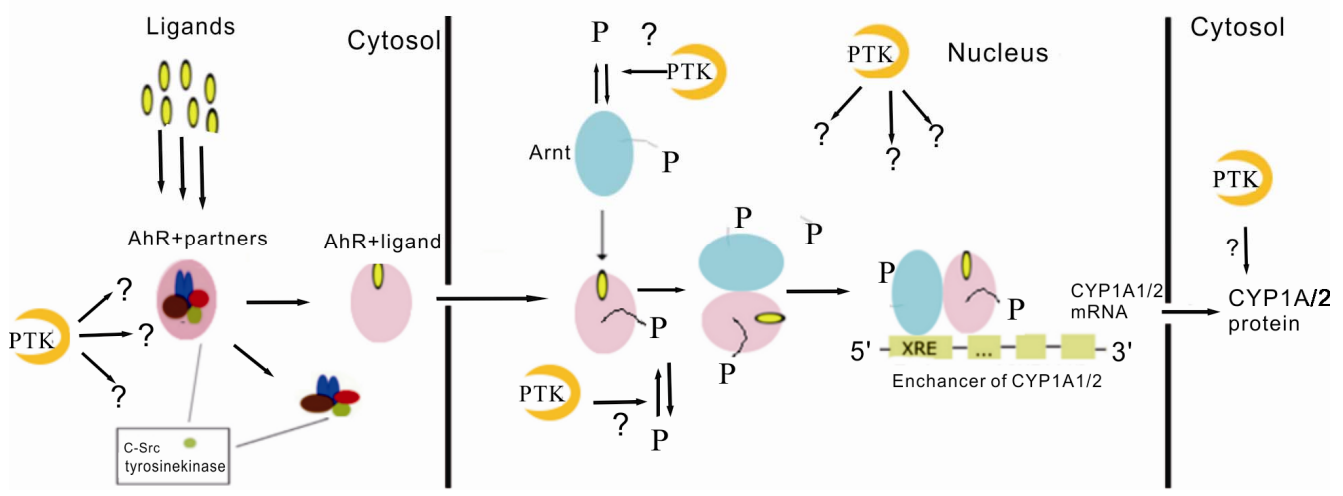

Figure 4. The scheme of the AhR-dependent signal transduction. Before ligand binding AhR locates in cytoplasm in complex with other proteins (Hsp90, XAP2, p23, c-Src). Ligand binding leads to translocation of AhR to nuclei where it forms a dimer with Arnt. AhR/Arnt dimer binds enhancer of target gene which results in theirs expression. PTKs may participate in the modulation of CYP1A expression by phosphorylating/dephosphorylating AhR or some components of the AhR-dependent signal transduction pathway. O-Ligand; - inactive AhR in complex with its protein partners; - activated AhR; -Arnt; P-phosphorylated protein; $P$ — protein-tyrosine kinase; XRE—xenobiotic responsive element, AhR — aryl hydrocarbon receptor; Arnt—Ah receptor nuclear translocator.

results could perhaps be explained by the differences in the experimental conditions: in vivo using intact animals versus in vitro using cell cultures exposed to PAH-like compounds. Other explanations of discrepancies are possible: for example, it is known that genistein has a phytoestrogen function [28] and the estrogen receptor in turn has cross-talk with AhR [29]. But herbimycin A and geldanamycin are not phytoestrogens but affect CYP1A1 more strongly that genistein. It is possible that estrogen activity of genistein is antagonistic to AhR activation.

Such a speculation put forward Rowlands et al. [28] in whose paper described that genistein negatively regulates CYP1A1 in vivo. Another point is the following. It is known that some substances, for example, tocopherol [30], menadione [31] can cause a weak CYP1A1 induction but in combined with a "classic", strong CYP1A1 inducer causes a decrease of CYP1A1 expression compared to induction caused by strong CYP1A1 inducer only [32] (and data by Sidorova et al., unpublished). The mechanism of these phenomena now is not fully clear. Given that the literature data about effects of tyrosine kinase inhibitors on CYP1A1 induction are described exactly the combined actions we can assume a similar situation in this case. More detail interpretation of data including discrepancies with the literature data needs future investigations.

Thus, our data demonstrate that none of the PTK inhibitors reduced CYP1A activity, the CYP1A mRNA level or the CYP1A protein level. Therefore, the PTKs do not increase CYP1A expression in the rat liver.

The respective effects of the PTK inhibitors used on CYP1A1 and CYP1A2 were different. All increased CYP1A1 activity and the CYP1A1 protein level, herbimycin A and geldanamycin increased the CYP1A1 mRNA level.
CYP1A2 activity and the CYP1A2 mRNA level remained unaffected on all occasions, the CYP1A2 protein level was increased, but not so much as the CYP1A1 protein level.

We therefore propose that PTKs reduce CYP1A1 expression. It is also possible that PTKs phosphorylate AhR or some components of the AhR-dependent signaling pathway, which results in the negative regulation of CYP1A1 expression.

The only known way of CYP1A1 activation is transcriptional activation through the AhR-dependent signal transduction pathway [33]. CYP1A2 activation can occur both at the transcriptional level through the AhR-dependent or AhR-independent signal transduction pathway [34] and at the post-transcriptional level [35]. The difference between CYP1A1 and CYP1A2 in their response to PTK inhibitors could perhaps be attributed to the difference in their mechanisms of activating gene expression.

Thus, we conclude that PTK inhibitors genistein, herbimycin A and geldanamycin do not account for the ne gative regulation of CYP1A but act as positive regulators. We assume that PTKs may act as negative regulators of CYP1A1 by phosphorylating/dephosphorylating AhR or some components of the AhR-dependent signal transduction pathway.

\section{REFERENCES}

[1] Denison, M.S. and Nagy, S.R. (2003) Activation of the aryl hydrocarbon receptor by structurally diverse exogenous and endogenous chemicals. Annual Review of Pharmacology and Toxicology, 43, 309-334. doi:10.1146/annurev.pharmtox.43.100901.135828 
[2] Ma, Q. (2001) Induction of CYP1A1. The AhR/DRE paradigm: Transcription, receptor regulation, and expanding biological roles. Current Drug Metabolism, 2, 149-164. doi: $10.2174 / 1389200013338603$

[3] Enan, E. and Matsumura, F. (1996) Identification of c-Src as the integral component of the cytosolic $\mathrm{Ah}$ receptor complex, transducing the signal of 2,3,7,8-tetrachloro-dibenzo- $p$-dioxin (TCDD) through the protein phosphorylation pathway. Biochemical Pharmacology, 52, 1599-1612. doi:10.1016/S0006-2952(96)00566-7

[4] Fujii-Kuriyama, Y. and Kawajiri, K. (2010) Molecular mechanisms of the physiological functions of the aryl hydrocarbon (dioxin) receptor, a multifunctional regulator that senses and responds to environmental stimuli. Proceedings of the Japan Academy, Series B, Physical and Biological Sciences, 86, 40-53. doi:10.2183/pjab.86.40

[5] Ma, C., Marlowe, J.L. and Puga, A. (2009) The aryl hydrocarbon receptor at the crossroads of multiple signaling pathways. Experientia Supplementum, 99, 231-257. doi:10.1007/978-3-7643-8336-7 9

[6] Delescluse, C., Lemaire, G., de Sousa, G., and Rahmani, R. (2000) Is CYP1A1 induction always related to AHR signaling pathway? Toxicology, 153, 73-82. doi:10.1016/S0300-483X(00)00305-X

[7] Levine, S.L. and Perdew, G.H. (2001) Aryl hydrocarbon receptor (AhR)/AhR nuclear translocator (ARNT) activity is unaltered by phosphorylation of a periodicity/ARNT/ single-minded (PAS)-region serine residue. Molecular Pharmacology, 59, 557-566.

[8] Oesch-Bartlomowicz, B. and Oesch, F. (2004) Modulation of mutagenicity by phosphorylation of mutagenmetabolizing enzymes. Archives of Biochemistry and Biophysics, 423, 31-36. doi:10.1016/j.abb.2003.11.020

[9] Oesch-Bartlomowicz, B. and Oesch, F. (2005) Phosphorylation of cytochromes P450: First discovery of a posttranslational modification of a drug-metabolizing enzyme. Biochemical and Biophysical Research Communications, 338, 446-449. doi:10.1016/j.bbrc.2005.08.092

[10] Robinson, D.R., Wu, Y.M. and Lin, S.F. (2000) The protein tyrosine kinase family of the human genome. Oncogene, 19, 5548-5557. doi:10.1038/sj.onc.1203957

[11] Vlahovic, G. and Crawford, J. (2003) Activation of tyrosine kinases in cancer. Oncologist, 8, 531-538. doi:10.1634/theoncologist.8-6-531

[12] Burke, M.D., Thompson, S., Elcombe, C.R., Halpert, J., Haaparanta, T. and Mayer, R.T. (1985) Ethoxy-, pentoxyand benzyloxyphenoxazones and homologues: A series of substrates to distinguish between different induced cytochromes P-450. Biochemical Pharmacology, 34, 3337-3345. doi:10.1016/0006-2952(85)90355-7

[13] Lowry, O.H., Rosebrough, N.J., Farr, A.L. and Randall, R.J. (1951) Protein measurement with the Folin phenol reagent. The Journal of Biological Chemistry, 193, 265275.

[14] Morris, D.L. and Davila, J.C. (1996) Analysis of rat cytochrome P450 isoenzyme expression using semi-quantitative reverse transcriptase-polymerase chain reaction (RT-PCR). Biochemical pharmacology, 52, 781-792. doi:10.1016/0006-2952(96)00390-5

[15] Walker, N.J., Portier, C.J., Lax, S.F., Crofts, F.G. Li, Y., Lucier, G.W. and Sutter, T.R. (1999) Characterization of the dose-response of CYP1B1, CYP1A1, and CYP1A2 in the liver of female Sprague-dawley rats following chronic exposure to 2,3,7,8-tetrachlorodibenzo-p-dioxin. Toxicology and Applied Pharmacology, 154, 279-286. doi:10.1006/taap.1998.8595

[16] Adams, N.H., Levi, P.E., and Hodgson, E. (1993) Regulation of cytochrome $P-450$ isozymes by methylenedioxyphenyl compounds. Chemico-Biological Interactions, 86, 255-274. doi:10.1016/0009-2797(93)90101-4

[17] Laemmli, U.K. (1970) Cleavage of structural proteins during the assembly of the head of bacteriophage T4. Nature, 227, 680-685. doi:10.1038/227680a0

[18] Grishanova, A.Yu and Lyakhovich, V.V. (1992) Using of antibodies to cytochrome P-450 library in xenobiotics metabolism studies. In: Archakov, A. and Bachmanova, G., Eds., Cytochrome P-450: Biochemistry and Biophysics, INCO-TNC, Moscow, 525-528.

[19] Schirmer, K., Chan, A.G. and Bols, N.C. (2000) Transitory metabolic disruption and cytotoxicity elicited by benzo[a]pyrene in two cell lines from rainbow trout liver. Journal of Biochemical and Molecular Toxicology, 14, 262-276.

doi:10.1002/1099-0461(2000)14:5<262::AID-JBT5>3.0. $\mathrm{CO} ; 2-2$

[20] Lemaire, G., Delescluse, C., Pralavorio, M., Ledirac, N., Lesca, P. and Rahmani, R. (2004) The role of protein tyrosine kinases in CYP1A1 induction by omeprazole and thiabendazole in rat hepatocytes. Life Sciences, 74, 22652278. doi:10.1016/j.1fs.2003.09.056

[21] Kikuchi, H., Hossain, A., Yoshida, H. and Kobayashi, S. (1998) Induction of cytochrome P-450 1A1 by omeprazole in human HepG2 cells is protein tyrosine kinasedependent and is not inhibited by alpha-naphthoflavone. Archives of Biochemistry and Biophysics, 358, 351-358. doi:10.1006/abbi.1998.0869

[22] Wiseman, S.B. and Vijayan, M.M. (2007) Aryl hydrocarbon receptor signaling in rainbow trout hepatocytes: Role of hsp90 and the proteasome. Comparative Biochemistry and Physiology, Part C, 146, 484-491.

[23] Song, Z. and Pollenz, R.S. (2002) Ligand-dependent and independent modulation of aryl hydrocarbon receptor localization, degradation, and gene regulation. Molecular Pharmacology, 62, 806-816. doi:10.1124/mol.62.4.806

[24] Hoelper, P., Faust, D., Oesch, F. and Dietrich, C. (2005) Evaluation of the role of c-Src and ERK in TCDD-dependent release from contact-inhibition in WB-F344 cells. Archives of Toxicology, 79, 201-207. doi:10.1007/s00204-004-0624-6

[25] Shertzer, H.G., Puga, A., Chang, C., Smith, P., Nebert, D.W., Setchell, K.D. and Dalton, T.P. (1999) Inhibition of CYP1A1 enzyme activity in mouse hepatoma cell culture by soybean isoflavones. Chemico-Biological Interactions, 123, 31-49. doi:10.1016/S0009-2797(99)00121-0

[26] Backlund, M., Johansson, I., Mkrtchian, S. and Ingelman-Sundberg, M. (1997) Signal transduction-mediated 
activation of the aryl hydrocarbon receptor in rat hepatoma H4IIE cells. The Journal of Biological Chemistry, 272, 31755-31763.

[27] Gradin, K., Whitelaw, M.L., Toftgard, R., Poellinger, L. and Berghard, A. (1994) A tyrosine kinase-dependent pathway regulates ligand-dependent activation of the dioxin receptor in human keratinocytes. The Journal of Biological Chemistry, 269, 23800-23807.

[28] Rowlands, J.C., He, L., Hakkak, R., Ronis, M.J. and Badger, T.M. (2001) Soy and whey proteins downregulate DMBA-induced liver and mammary gland CYP1 expression in female rats. The Journal of Nutrition, 131, 32813287.

[29] Harper, P.A., Riddick, D.S. and Okey, A.B. (2006) Regulating the regulator: Factors that control levels and activity of the aryl hydrocarbon receptor. Biochemical Pharmacology, 72, 267-279. doi:10.1016/j.bcp.2006.01.007

[30] Sidorova, Y.A., Grishanova, A.Y. and Lyakhovich, V.V. (2004) Transcriptional activation of cytochrome P450 1A1 with alpha-tocopherol. Bulletin of Experimental Biology and Medicine, 138, 233-236.

[31] Sidorova, Y.A., Grishanova, A.Y. and Lyakhovich, V.V. (2005) Rat hepatic CYP1A1 and CYP1A2 induction by menadione. Toxicology Letters, 155, 253-258. doi:10.1016/j.toxlet.2004.10.001

[32] Sidorova, Y.A. and Grishanova, A.Y. (2005) Inhibitory effect of alpha-tocopherol on benzo(a)pyrene-induced CYPA1 activity in rat liver. Bulletin of Experimental Biology and Medicine, 140, 517-520. doi:10.1007/s10517-006-0012-8

[33] Whitlock J.P.Jr. (1999) Induction of cytochrome P4501A1. Annual Review of Pharmacology and Toxicology, 39 103-125. doi:10.1146/annurev.pharmtox.39.1.103

[34] Quattrochi, L.C., Vu, T. and Tukey, R.H. (1994) The human CYP1A2 gene and induction by 3-methyl-cholanthrene. A region of DNA that supports AH-receptor binding and promoter-specific induction. The Journal of Biological Chemistry, 269, 6949-6954.

[35] Raffalli-Mathieu, F. Geneste, O. and Lang, M.A. (1997) Characterization of two nuclear proteins that interact with cytochrome P-450 1A2 mRNA. Regulation of RNA binding and possible role in the expression of the CYP1A2 gene. European Journal of Biochemistry, 245, 17-24. doi:10.1111/j.1432-1033.1997.00017.x 